\title{
DESAFIOS NA FORMAÇÃO EM SERVIÇO DA RESIDÊNCIA MULTIPROFISSIONAL EM SAÚDE*
}

\author{
Kércia Rocha Andrade \\ Alessandra Genú Pacheco
}

\section{Introdução}

No conjunto dos Programas de Residência em Saúde, os referidos podem ser divididos em uniprofissionais e multiprofissionais. No caso da Residência Médica, por exemplo, essa modalidade compõe a Residência em Área Profissional da Saúde, ou seja, uma formação destinada apenas a uma categoria profissional. Já a Residência Multiprofissional em Saúde como o próprio nome sinaliza, destina-se aos profissionais graduados em diferentes áreas da saúde.

A Residência Multiprofissional em Saúde (Remu) constitui-se uma modalidade de PósGraduação lato sensu no Brasil, caracterizada pela formação em serviço e destinada aos trabalhadores da saúde, com exceção dos profissionais da Medicina.

O marco legal-normativo da Residência Multiprofissional enquanto modalidade de PósGraduação lato sensu em saúde, ocorre por meio da Lei no 11.129, de 30 de junho de 2005 e pela Portaria Interministerial $n^{\circ} 2.117$, de 03 de novembro de 2005, que regulamentam as residências em saúde, por meio do Programa de Bolsas para Educação pelo Trabalho, como também estabeleceu a criação da Comissão Nacional de Residência Multiprofissional em Saúde (CNRMS), com vista a credenciar, certificar, avaliar e acompanhar os Programas de Residência Multiprofissional em Saúde. Já a coordenação local de cada programa de Remu fica a cargo da Comissão de Residência Multiprofissional (COREMU), que será responsável pela elaboração do seu próprio Projeto Pedagógico (PP). Cada projeto apresenta as diretrizes pedagógicas, características e particularidades de cada programa de residência, além de estabelecer o perfil dos residentes, indicando as habilidades e competências dos mesmos, assim como indicam a matriz curricular dessa formação em serviço.

Nesse sentido, vale destacar que o reconhecimento legal da Remu, enquanto uma modalidade de pós-graduação, resulta do processo histórico de luta da classe trabalhadora, em particular no caso da saúde, por meio de críticas e reivindicações a partir do movimento de Reforma Sanitária, que, dentre inúmeras bandeiras de luta, pleiteiam melhores condições dos serviços do Sistema Único de Saúde (SUS), bem como sinalizavam a importância de uma formação e atuação profissional em saúde com qualidade e em consonância com as necessidades da população assistida. A materialização dessas reivindicações ocorre de diferentes maneiras, a exemplo das mudanças curriculares dos cursos da área de saúde, a instituição do Programa de Educação Tutorial em Saúde (PET/Saúde), o Programa Nacional de Reorientação da Formação Profissional em Saúde (Pró-Saúde), Residência em Saúde e outras iniciativas.

No caso dos Programas de Residência Multiprofissional em Saúde, eles foram consolidados num cenário de disputa de diferentes projetos societários, como veremos adiante, e, mesmo num contexto de conflitos, a partir do ano de 2005 a Remu passou a ser regulada pelo

* DOI- 10.29388/978-65-81417-27-7-0-f.47-57 
Ministério da Educação (MEC) e pelo Ministério da Saúde (MS), que são responsáveis pela promoção, organização, avaliação e normatização dessa modalidade de formação em serviço.

Atualmente, a Residência Multiprofissional em Saúde se caracteriza pelo regime de dedicação exclusiva, com uma carga horária semanal de 60 horas, subdividida entre $80 \%$ do tempo para atividades formativas práticas e $20 \%$ dedicado às atividades teóricas. Além disso, a residência em saúde tem duração de 24 meses, correspondendo ao total de 5760 (cinco mil, setecentos e sessenta) horas, sendo que os(as) Residentes têm direito a um (01) dia de folga semanal e 30 (trinta) dias consecutivos de férias, além do recebimento de uma Bolsa de Educação pelo Trabalho no valor $\mathrm{R} \$ 3.330,43$ (três mil, trezentos e trinta reais e quarenta e três centavos), que garante as condições mínimas de permanência na formação em serviço.

Essa carga horária da formação profissional na Remu é distribuída entre atividades práticas, com a maior parte do tempo, e atividades teóricas ou teórico-práticas A integração desses três eixos: prático, teórico e teórico-prático compõem o projeto pedagógico da Residência Multiprofissional em Saúde.

Por eixo prático entende-se o treinamento em serviços da área da saúde, ou seja, corresponde à prática profissional. No caso de uma residência multidisciplinar, as especificidades de cada profissão são resguardadas. Apesar dos Residentes serem profissionais graduados, há necessidade da supervisão técnica da prática profissional por parte dos preceptores de cada área. O preceptor constitui-se o trabalhador dos serviços de saúde responsável por orientar os residentes no eixo prático. No caso do Serviço Social, por exemplo, o residente desta área só pode atuar num serviço de saúde sob supervisão de um(a) assistente social.

Outro eixo que compõe a formação profissional da Remu é o eixo teórico, que equivale às atividades de aprendizagem, isto é, conhecimento teórico que pode ocorrer por meio de aulas, pesquisas, estudos individuais e em grupo, e outras atividades formativas sob orientação de docentes, tutores, preceptores e/ou outros profissionais convidados. E o eixo teórico-prático representa as atividades de discussão de caso clínico ou de discussão de outros aspectos dos serviços da saúde, ou seja, são atividades que relacionam o conhecimento teórico com as demandas práticas trazidas pela realidade, também sob orientação e supervisão de docente, tutor, preceptor e/ou outros trabalhadores da saúde.

Essas particularidades do regime de dedicação exclusiva, da formação em serviço, da bolsa de educação pelo trabalho, da carga horária de $60 \mathrm{~h}$ semanais e dos 03 eixos do projeto pedagógico, bem como outras particularidades, fomentam um grande debate em torno das Residências em Saúde, em especial se representam uma formação profissional em saúde ou uma nova configuração do mundo do trabalho, reconfigurada sob a formação em serviço.

$\mathrm{Na}$ perspectiva de uma defesa da Remu enquanto espaço formativo e de resistência, é importante salientar que essa modalidade de ensino, via bolsas de educação aos trabalhadores da saúde, é crucial para o desenvolvimento e reafirmação dos serviços do Sistema Único de Saúde (SUS). Por trabalhadores da saúde contemplados pela residência multiprofissional, compreendem-se as profissões reconhecidas pela Resolução do Conselho Nacional de Saúde (CNS) $n^{\circ}$ 287/1998, quais sejam: Biomedicina, Ciências Biológicas, Educação Física, Enfermagem, Farmácia, Fisioterapia, Fonoaudiologia, Medicina Veterinária, Nutrição, Odontologia, Psicologia, Saúde Coletiva, Serviço Social e a Terapia Ocupacional.

Diante do exposto e mesmo com o reconhecimento legal-normativo da Remu nos últimos anos enquanto formação lato sensu em saúde, estudos como Andrade (2015; 2020), Castro (2013); Closs (2010; 2013); CFESS (2017), Mendes (2013), Rodrigues (2011; 2016), Rosa (2012), 
Santana; Campos; Sena (1999), Schmaller (2012), Silva (2018), entre outros, sinalizam para o desafio em consolidar a Residência Multiprofissional no Brasil como formação profissional e não trabalho.

Esse espaço formativo é permeado por vários desafios, primeiro por ser uma experiência relativamente nova para os profissionais da saúde; segundo, pela dificuldade em ser consolidado como formação em serviço e não uma nova configuração do trabalho; terceiro, por ser uma formação profissional instituída num campo de disputa por diferentes projetos ideopolíticos e outros debates.

No âmbito dos projetos ideológicos em disputa, há, de um lado, uma posição que defende a Residência Multiprofissional em Saúde enquanto espaço formativo para os trabalhadores da saúde em conformidade com as diretrizes do movimento de reforma sanitária e de defesa do SUS, ou, em outras palavras, enquanto formação profissional para melhoria do sistema público, gratuito e de qualidade para todos. Por outro lado, há o projeto neoliberal de contrarreforma do Estado brasileiro, que visa o fortalecimento do capital em detrimento do desenvolvimento das políticas públicas (BRAVO, 2008). Um projeto que segue uma agenda neoliberal, a qual compreende a Remu a partir da lógica do capital, como espaço de trabalho e de produtividade em saúde.

A própria estrutura da Remu subdividida em atividades formativas práticas (80\%) e atividades teóricas $(20 \%)$ prenuncia a hegemonia do projeto neoliberal neste processo. Supondo que essa estrutura fosse rigorosamente seguida, subtraindo $20 \%$ de uma carga horária de $12 \mathrm{~h}$ por dia, ainda restariam cerca de $09 \mathrm{~h} 30 \mathrm{~min}$ de formação em serviço, superando as $8 \mathrm{~h}$ de jornada laboral de um trabalhador contratado pela Empresa Brasileira de Serviços Hospitalares (EBSERH), por exemplo.

Considerando o déficit de recursos humanos que se apresentava na saúde pública brasileira, mesmo antes da pandemia, já se observava com frequência a situação de um mesmo preceptor supervisionando dois residentes em cenários de prática distintos, visto que é requerido do próprio preceptor que, temporariamente, 'cobrisse' mais de um setor, até que o quadro de servidores fosse restabelecido - situação bastante reincidente, mas sempre em caráter declaradamente excepcional.

Ocorre que, quando um residente permanece sem preceptor em um cenário de prática, as 09h30min de 'formação em serviço' são descaracterizadas e passam a ser uma jornada de 09h30min de trabalho, um período superior às $8 \mathrm{~h}$ diárias de um servidor contratado, com a desvantagem de não ter direito trabalhista algum assegurado. Reitera-se que essa realidade é anterior à pandemia e se atrela ao avanço do neoliberalismo, com seus inúmeros impactos no mundo do trabalho.

\section{Consolidação da Formação em Serviço da REMU}

A criação da Comissão Nacional de Residência Multiprofissional em Saúde (CNRMS), em 2005, representou um marco fundamental para a formação dessa modalidade de residência, especialmente pela organização, reconhecimento e consolidação dos Programas de Remu no Brasil. 
A implantação dessa Comissão colocou um novo desafio para a consolidação da Residência e também uma nova agenda política para os movimentos implicados nessa formação: a construção de critérios mínimos para o processo de credenciamento, a avaliação e o reconhecimento dos programas de Residência já existentes e a construção de câmaras técnicas, contando com a participação de conselhos e associações das profissões da saúde, configurando-se como novos atores que ingressam nos espaços públicos de discussão sobre essa formação (CLOSS, 2013, p. 68).

Nesse contexto e a partir da articulação interministerial entre Ministério da Educação (MEC) e Ministério da Saúde (MS), foi promulgada uma série de normatizações que estabeleciam como deveria ser a atuação da COREMU, isto é, indicavam diretrizes nacionais de como os Programas de Residência deveriam proceder na condução dessa formação em serviço.

Desde 2011, a CNRMS promulgou várias resoluções que tratavam: do preenchimento de vagas e desistências; estabelecimento da certificação; transferência dos profissionais residentes para outros programas de Residência; sobre as licenças (maternidade, paternidade, caso de óbito na família, folgas, férias e trancamento de matrícula); a instituição das Câmaras Técnicas; formulação e redefinição das diretrizes gerais para os Programas de Remu; criação do Sistema de Informação da CNRMS (SisCNRMS); fomento do Banco de Avaliadores da CNRMS; constituição da Comissão de Residência Multiprofissional (COREMU) dos programas, destacando os processos de avaliação, supervisão e regulação, como também, estabeleceu como deveria ocorrer o funcionamento, a organização e as atribuições da COREMU; além de orientações para os Residentes egressos, dentre outras resoluções que foram essenciais para o desenvolvimento da Remu.

No entanto, no decorrer do processo histórico de desenvolvimento da Residência Multiprofissional em Saúde no Brasil inúmeros desafios foram postos ao funcionamento da Residência. De um lado, importante destacar alguns avanços, tais como, o reconhecimento da Remu como uma modalidade de Pós-Graduação lato sensu, uma formação profissional articulada com os serviços de saúde, a articulação do tripé ensino-pesquisa-extensão, o recebimento de uma Bolsa de Educação pelo Trabalho, a Licença Maternidade/Paternidade, entre outros fatos.

Do outro lado, identificam-se os desafios para a Remu: a ingerência da agenda neoliberal na condução da Remu; estabelecendo como prioridade a prática profissional em detrimento da formação em serviço e da educação em saúde; a intensa carga horária semanal e sua distribuição com a maior parte do tempo para o eixo prático também corrobora a primazia pela atuação profissional, como já foi dito. Outros desafios também são colocados à consolidação da Remu, como: a dificuldade, por parte do MEC e MS, do reconhecimento dos Fóruns de articulação dos segmentos que compõem a Remu; constante afastamento dos representantes dos residentes dos espaços de decisões da Residência; e insuficiente divulgação e transparência dos dados da Remu.

Como visto anteriormente, a CNRMS desempenha a função de nortear a condução dos Programas de Remu; no entanto, desde 2019 o Ministério da Educação não convoca a referida comissão e a falta de reuniões repercute diretamente na condução da Remu, a exemplo do contexto decorrente da pandemia ocasionada pelo Covid-19:

Considerando que caberia à Comissão Nacional de Residência Multiprofissional em Saúde (CNRMS), a responsabilidade de emitir orientações para a inédita 
situação de pandemia que estamos vivendo, mas a mesma não é convocada pelo Ministério da Educação desde maio de 2019, em que pese a infinidade de denúncias e consultas remetidas aos Fóruns de Coordenadores, de Preceptores e Tutores e de Residentes em Saúde ou aos representantes das associações de ensino e das federações sindicais em forma de apelo, as quais não puderam ser apuradas até o momento, já tendo sido trazidas por todos esses segmentos à CIRHRT/CNS ${ }^{1}$ (MINISTÉRIO DA SAÚDE/ CONSELHO NACIONAL DE SAÚDE, 2020, p. 4).

Nesse contexto, a partir de março de 2020, quando eclodiu a pandemia do Covid-19 no Brasil, os profissionais inseridos na Remu, como Residentes, Preceptores, Tutores e Coordenadores precisavam do posicionamento da CNRMS para saber como conduzir a Remu durante a pandemia. Na ausência de orientações por parte da CNRMS, outras entidades se posicionaram a respeito da formação e atuação profissional dos Residentes nessa conjuntura adversa, a exemplo do Conselho Nacional de Saúde (CIRHRT/CNS), que instituiu o Parecer Técnico no 106/2020, validado pela Recomendação no 018, de 26 de março de $2020^{2}$, que tem como intuito "[...] um mínimo de padrão de segurança ao alcance de coordenadores, preceptores, tutores, residentes e sociedade em geral relativamente ao ordenamento da formação de profissionais de saúde" (MINISTÉRIO DA SAÚDE/ CONSELHO NACIONAL DE SAÚDE, 2020, p. 5).

O CNS estabeleceu 31 recomendações neste Parecer Técnico nº 106/2020, dentre elas destacam-se as seguintes orientações, com relação ao eixo teórico: suspensão das atividades teóricas presenciais, com a possibilidade do cumprimento de atividades pedagógicas via remoto; suspensão de eventos acadêmicos e científicos; sugestão da incorporação nos Trabalhos de Conclusão de Residência dos temas pertinentes à conjuntura do Covid-19; dentre outras.

Interessante destacar que, ao tratar do eixo teórico, todas as recomendações foram direcionadas pela suspensão das atividades presenciais e a indicação pelo ensino remoto. Com ressalva de uma recomendação, que sinaliza para em caso de retorno das atividades teóricas presenciais, cada programa de residência deveria elaborar um plano de readequação curricular. No que se refere às atividades práticas e teórico-práticas, o referido Parecer Técnico estabelece o cumprimento das $48 \mathrm{~h}$ semanais, correspondente aos $80 \%$ do eixo prático já preconizado pelas diretrizes gerais da Remu:

3- Manter as atividades práticas e teórico-práticas dos residentes em saúde, respeitando o limite de $80 \%$ (48 horas) da carga horária semanal. As atividades teórico-práticas, neste momento, devem acompanhar prioritariamente as ações de mobilização do setor da saúde na reorganização de serviços, redes, políticas e ações de participação popular ou controle social, resguardando-se a presença de residentes aos mesmos termos de modalidade previstos por tais atividades, inclusive a presença por meio de tecnologias de interação e comunicação remotas (Idem, 2020, p. 6).

\footnotetext{
${ }^{1}$ Comissão Intersetorial de Recursos Humanos e Relações de Trabalho do Conselho Nacional de Saúde (CIRHRT/CNS).

2 A aprovação da recomendação ocorreu durante a 64ª Reunião Extraordinária do Conselho Nacional de Saúde, em 10 de julho de 2020, por deliberação do Plenário do CNS (Idem, 2020, p. 1).
} 
Diante dessa conjuntura catastrófica, urge refletir acerca da formação na Residência Multiprofissional em Saúde. Por mais avanços pedagógicos que aconteçam no processo de consolidação da residência, ainda se identifica um entendimento confuso da formação em serviço, centrado prioritariamente na prática profissional. Concepção errônea que, segundo Rodrigues (2016), pode repercutir em alguns equívocos, tais como, a ilusão que o profissional residente poderá suprir a ausência de recursos humanos dos serviços de saúde.

\begin{abstract}
Inicialmente, equipes de residentes compostas com áreas profissionais que não estão presentes nos serviços. Com a concepção das contradições que perpassam o real, esta questão pode, potencialmente, ser uma riqueza, pois a interação entre as equipes que passam a compor o conjunto de trabalhadores nos serviços, potencializa a reflexão, e ao agregar novos sujeitos exige uma recomposição, um aprendizado e articulações que envolvem a todos. Por outro lado, pode trazer expectativas de que, aquele profissional, necessário no campo da política de saúde, venha a suprir a ausência daquela área, inserindo-se em uma condição diferenciada, mais marcada pela execução das demandas dos serviços em detrimento à condição de formação. O peso maior centra-se no trabalho e não na formação (RODRIGUES, 2016, p. 78).
\end{abstract}

Tratar a Remu enquanto modalidade de Pós-Graduação lato sensu, constitui-se um ato de resistência e de defesa da formação em serviço na saúde, especialmente nesse contexto de ofensiva neoliberal, aprofundado pela pandemia do Covid-19. Numa conjuntura de caráter emergencial dos serviços de saúde, haverá um grande desgaste dos trabalhadores da saúde e das suas condições de trabalho, como também um aumento do número de óbitos e afastamentos do local de trabalho entre os profissionais de saúde. Logo, esse contexto resultará em implicações para a formação profissional dos residentes.

Com base nesses desafios postos à formação em saúde, algumas entidades das categorias profissionais manifestaram seu posicionamento diante da atuação dos residentes no contexto da pandemia do Covid-19, a exemplo do Serviço Social, como veremos a seguir, que dentre várias iniciativas, também apresentou seu posicionamento por meio de uma manifestação elaborada pela Associação Brasileira de Ensino e Pesquisa em Serviço Social (ABEPSS), publicada em 07 de maio de 2020.

Nesse documento, a partir da compreensão de que os/as assistentes sociais residentes fazem parte da linha de frente de combate à pandemia, a ABEPSS destaca sete itens primordiais que orientam os programas de Remu nos quais se inserem esses profissionais: (1) considerando a gravidade do contexto pandêmico, as atividades práticas que forem mantidas devem ser todas voltadas ao urgente combate da pandemia de COVID-19; (2) o acompanhamento teórico se faz ainda mais necessário e não pode ser eliminado tampouco subestimado - no máximo realizado na modalidade remota emergencial, para manter a segurança dos profissionais envolvidos; (3) o preceptor continua sendo um sujeito imprescindível no processo formativo, sendo portanto inviável que qualquer residente permaneça sozinho nos cenários de prática; (4) as condições adequadas de trabalho devem ser asseguradas, sobretudo no que se refere aos EPIs e ao pagamento regular das bolsas de educação por trabalho; (5) os/as residentes que fizerem parte de grupo de risco devem ser afastados ou remanejados para home office, sempre que possível; (6) os/as residentes que forem contaminados pela COVID-19 devem ser mantidos em isolamento social e manter o tempo de quarentena orientado pelas secretarias de saúde em cuja abrangência 
se encontrem; (7) a excepcionalidade do contexto pandêmico não autoriza de modo algum que os/as assistentes sociais residentes sejam impelidos a atividades práticas que extrapolem suas competências e atribuições profissionais.

Considerando a ausência de orientação da CNRMS, a manifestação da ABEPSS foi de fundamental importância, ainda que se saiba que esses sete pontos elencados acima servem muito mais como parâmetros que fortalecem o projeto democrático formativo na disputa cotidiana contra o projeto neoliberal de trabalho, do que como elementos impeditivos da fragilização da Remu como formação, que segue acontecendo mais intensamente do que antes da pandemia.

Dos elementos apontados pela ABEPSS, destacam-se quatro características principais que marcam esse aprofundamento do projeto neoliberal de Remu como trabalho desregulamentado e precarizado: a insuficiência de EPIs asseguradas pelos serviços que se constituem como cenários de prática do processo formativo, deixando à cargo do próprio residente sua segurança sanitária; o atraso no pagamento das bolsas de educação pelo trabalho em alguns programas de Remu, deixando à cargo do próprio residente sua segurança material; e a conjunção entre a reincidente ausência de preceptoria direta e a imediata suspensão das atividades teóricas presenciais (desde o início da pandemia), com a orientação de que sejam substituídas por EaD - conjunção que aponta a alarmante tendência de que o residente também estaria sendo responsabilizado quase sozinho pela sua própria formação.

\section{A formação do Serviço Social na REMU face à subjetivação neoliberal}

Esses quatro principais impactos que afetaram a residência multiprofissional durante a pandemia corroboram o desafio abordado aqui de consolidar a Remu como formação e não como trabalho, oportunizando uma análise alternativa sobre este antigo entrave, a partir da qual se projetará um horizonte de enfrentamento do referido desafio. Esta análise tenta aproximar a ideia de subjetividade neoliberal - esmiuçada pelos franceses Pierre Dardot e Christian Laval - ao debate sobre os Programas de Remu, permitindo compreender dois fatos principais: (1) que a tendência de consolidação da residência multiprofissional como trabalho se fundamenta numa racionalidade neoliberal homogeneizadora de todas as esferas de vida, universalizando o discurso empresarial para todos os espaços; (2) que, para se opor à cultura neoliberal, há que se criar contra cultura, ou contra conduta, a qual pode se dar principalmente dentro da relativa autonomia dos eixos teóricos, inseridos numa matriz curricular mais crítica, mais problematizadora da organização produtiva capitalista na qual a política de saúde se insere.

Dardot e Laval (2016) oferecem uma exposição detalhada desta subjetividade neoliberal na segunda parte da obra "A nova razão do mundo", onde explicitam como a sociedade neoliberal "homogeneizou" o modelo de empresa privada, o qual pressupõe que o sujeito deve estar sempre inteiramente envolvido com o seu trabalho. A expansão deste preceito capitalista para toda a vida dos indivíduos, dentro e fora dos seus espaços de trabalho, só é possível a partir da transfiguração construída pela máxima de 'trabalhar para a empresa como se fosse para si mesmo'. A suposição embutida na expressão 'como se' transforma o 'desejo do outro' (empresa capitalista ou o próprio capital) em 'desejo do sujeito': "Desde que o poder moderno se torne o Outro do sujeito, a construção das figuras tutelares do mercado, da empresa e do dinheiro tende exatamente a isso" (DARDOT; LAVAL, 2016, p. 327-328). 
Tal projeção é levada a um outro patamar quando esta 'cultura empresarial' produz uma nova subjetividade, na qual as pessoas agem como se fossem instituições empresariais e travam relações pessoais como se fossem relações ou negociações empresariais, com base em contrapartidas: "A racionalidade empresarial apresenta a vantagem incomparável de unir todas as relações de poder na trama de um mesmo discurso. (...) o léxico da empresa contém um potencial de unificação dos diferentes 'regimes de existência"' (DARDOT; LAVAL, 2016, p. 331). Desta forma, os antigos laços de solidariedade foram pouco a pouco sendo corroídos e ficaram sem substituto, na perspectiva de que o espírito da competitividade é levado para todos os aspectos da vida, produzindo indivíduos que se relacionam extensivamente tentando mostrar que uns são melhores que outros, orientados pelo princípio de não cooperação.

Neste contexto, o homem 'fabricado' como 'empresa de si mesmo' se reproduz a partir do ethos da autovalorização, que é individualista ao extremo, em seu substrato: "A empresa de si mesmo é uma 'entidade psicológica e social [...]', ativa em todos os domínios e presente em todas as relações. [...] A responsabilidade do indivíduo pela valorização do seu trabalho no mercado tornou-se um princípio absoluto.” (DARDOT; LAVAL, 2016, p. 335). É por causa desse ethos que se popularizam frases motivacionais como 'o seu futuro só depende de você', ou ainda os ultimatos 'é pegar ou largar!', 'quer ou não quer essa oportunidade?!', que esmagam a autoestima de quem sente na pele, a ferro e fogo, que 'sucesso ou fracasso' não dependem só de si, embora o concreto vivido frequentemente seja subvertido pela subjetivação do ethos neoliberal, invisibilizando a violenta realidade.

Dessa forma, as pessoas empreendem sacrificantes 'asceses de desempenho' para ocuparem um lugar na sociedade. Elas precisam ser as pessoas mais belas, as mais perfeitas, as mais inteligentes, as mais equilibradas, harmônicas, educadas, saudáveis, entre outros adjetivos, seguindo numa lista exaustiva e infindável. Não importa muito se a pessoa é realmente tudo aquilo que tenta mostrar, mas sim como todos os demais a percebem, não apenas no trabalho, mas em toda a sua vida, nas 24 horas do dia, por todos os ângulos possíveis. Os profissionais inseridos na Remu não estão imunes a essa racionalidade; muito pelo contrário, são expostos a sua reprodução no ambiente laboral por mais tempo e de modo mais intenso.

O novo dispositivo disciplinador do neoliberalismo é o desempenho, mas não sozinho. Dardot e Laval chamam de dispositivo desempenho/gozo, compreendendo 'gozo' como 'prazer', que por sua vez está diretamente associado ao 'sucesso' pretendido nas asceses de desempenho. Os dois grandes indicadores de subjetivação neoliberal são, portanto, a 'performance' e o 'gozo'. Para que esse dispositivo funcione e se reproduza, o indivíduo é instigado a libertar-se de qualquer limite na busca de prazer/sucesso, fazendo com que as asceses de desempenho não sejam vistas como um sofrimento, mas sim como caminhos escolbidos autonomamente para o alcance de seu próprio gozo:

Quando poder e liberdade subjetiva não são mais contrapostos, quando se estabelece que a arte de governar não consiste em transformar um sujeito em puro objeto passivo, mas conduzir um sujeito a fazer o que aceita querer fazer, a questão se apresenta sob uma nova luz. O novo sujeito não é mais apenas o do circuito produção/poupança/consumo, típico de um período consumado do capitalismo (DARDOT; LAVAL, 2016, p. 355). 
$\mathrm{Na}$ conclusão da referida obra (intitulada "O esgotamento da democracia liberal"), os autores apontam quatro traços que desenham a razão neoliberal: a ideia de que o mercado é construtivista; de que a essência do mercado é a concorrência; de que o Estado também é submetido à norma da concorrência; e de que o 'governo do outro com coerção' foi substituído pela governamentalidade, que é a formatação de uma subjetividade na qual cada um se impõe essa 'governamentalidade' e fiscaliza se todos os demais estão dentro dela.

Nessa conclusão, eles enfatizam a problemática da subjetivação, apontando-a como a grande estratégia do neoliberalismo e, ao mesmo tempo, como uma via de tensão e transformação. A subjetivação é um contexto cultural que dificulta que as pessoas pensem de um modo alternativo. Considerando que qualquer forma de governo requer uma subjetivação correspondente, é preciso criar um outro contexto, uma contracultura que permita o surgimento de um sujeito diferente do 'sujeito neoliberal'. A consequência dessa compreensão é o fato de que seria inútil constituir um novo governo enquanto a subjetividade continue sendo neoliberal, pois todas as mudanças seriam interpretadas do ponto de vista neoliberal.

$\mathrm{Na}$ literatura crítico social, muitos pensadores defendem o 'privilégio ontológico de exterioridade' para 'pensar diferente', aludindo a um 'privilégio' da classe social explorada para perceber a artificialidade de uma subjetividade não criada por ela. Dardot e Laval são enfáticos em dizer que essa teorização 'essencialista' não tem serventia para uma 'esquerda' que lida com processos teóricos concretos. É preciso construir o processo de demanda, um novo sujeito, uma nova subjetividade, pois a solução para a 'subjetividade heterônoma' é a criação de uma 'subjetividade autônoma'.

$\mathrm{Na}$ concepção deles, a verdadeira contracultura é uma 'torção' dos princípios neoliberais para se adequarem a uma nova subjetividade que está sendo formada pelos sujeitos. Nesse sentido, ocorre contracultura - ou contra conduta - quando se inaugura uma loja (dentro do mercado, portanto) que incentive a solidariedade e a cooperação, por exemplo. Seria preciso criar formas de desobediência dentro da 'obediência', segundo eles, opondo à 'razão neoliberal' a 'razão do comum', que viria a ser a razão alternativa da esquerda, uma razão 'cooperativa', em vez de competitiva.

A análise de Dardot e Laval contribui neste ensaio, portanto, para se compreender a dificuldade para enfrentar o desafio de consolidação da Remu como formação em um mundo homogeneizado por uma racionalidade que segue em uma direção completamente diferente. Destaca-se ainda a principal observação de que na razão neoliberal formada heteronomamente, o residente frequentemente se impõe aquela referida 'ascese de desempenho' e comemora cada sucesso de 'performance' - as excelentes avaliações ao final de cada rodízio, a nota máxima no TCR, prêmios etc. - muitas vezes não reconhecendo a auto exploração que se impõe e reproduz em cada uma de suas $60 \mathrm{~h}$ semanais.

\section{Considerações finais}

Propondo-se a pergunta sobre como romper com a racionalidade neoliberal que conflita com o projeto de formação em serviço da Remu, a leitura de Dardot e Laval permite a indicação de que um dos caminhos possíveis seria por meio de mudanças na matriz curricular da formação em saúde: uma mudança de cunho crítico, promovendo uma formação reflexiva a respeito das implicações dos determinantes sociais, políticos, culturais e econômicos sobre as condições de 
saúde no Brasil. Pensar aqui a matriz curricular da Remu como via de contra conduta à racionalidade neoliberal exige reconhecê-la como espaço privilegiado de reflexão e crítica.

Nesse sentido, são necessárias duas considerações para delinear esse currículo com declarada intenção de se contrapor à subjetivação neoliberal. A primeira delas é a constatação de que todo Projeto Pedagógico de Curso (PPC) é, invariavelmente, um projeto político pedagógico, ainda que a nomenclatura não seja explícita. Seja pela presença de conteúdos críticos, seja pela ausência, currículo algum se apresenta como neutro. Partindo-se deste pressuposto, há que se considerar elementos cruciais para a construção de um PPC crítico: que o processo de sua construção seja democrático, assegurando a participação de todos os atores envolvidos; que ele leve em consideração o território onde está inserido; que ele seja dinâmico e acompanhe as transformações da realidade e dos sujeitos que atende.

Além destes três elementos centrais para a construção de um PPC crítico, os Programas de Remu apresentam a qualidade de serem interdisciplinares, o que poderia ser um dado desimportante num PPC tradicional compartimentado, mas pode guardar um rico potencial emancipatório quando essa interdisciplinaridade é pensada do ponto de vista integrador em todos os processos, sejam práticos (formando profissionais mais preparados para o diálogo e o trabalho em equipe), sejam teóricos (promovendo compreensões e análises mais abrangentes da realidade), guardando a especificidade das competências profissionais e das atribuições privativas de cada área.

Finalmente, é preciso reconhecer que um PPC - reitera-se, sempre político - é espaço de poder e disputa dos projetos em tensão na sociedade - projeto radicalmente democrático e projeto neoliberal privatista. Essa disputa ocorrerá durante sua construção, sua implementação e subsequentes reformulações. Órfão de qualquer padrão tradicional, a diretriz da qual não se pode prescindir em seu processo é que ele jamais seja assumido como dado, mas que esteja afinado com a realidade concreta de seu entorno, bem como os sujeitos dessa realidade, permitindo o engendramento de uma subjetividade verdadeiramente autônoma, com base na 'razão do comum', desconstruindo gradualmente qualquer outra subjetividade imposta.

\section{Referências}

ANDRADE, K. R. A Formação Profissional do Assistente Social na Residência Multiprofissional em Saúde do HU/UFS. 2015. Dissertação (Mestrado em Serviço Social). Programa de Pós-Graduação em Serviço Social, Universidade Federal de Sergipe, São Cristóvão/SE, 2015.

ANDRADE, K. R. Residência Multiprofissional em Saúde: a formação em serviço no Brasil. 2020. Tese (Doutorado em Serviço Social). Programa de Estudos Pós-Graduados em Serviço Social, Pontifícia Universidade Católica de São Paulo, São Paulo/SP, 2020.

\section{ASSOCIAÇÃO BRASILEIRA DE ENSINO E PESQUISA EM SERVIÇO SOCIAL (ABEPSS). As residências em Saúde e o Serviço Social em tempos de} pandemia covid-19. Disponível em: http://www.abepss.org.br/noticias.html. Acesso em: 13 maio 2020. 
BRASIL. Ministério da Saúde. Conselho Nacional de Saúde. Recomendação $\mathbf{n}^{\mathbf{0}} \mathbf{0 1 8}$, de 26 de março de 2020. Disponível em: http://conselho.saude.gov.br/recomendacoes-cns/1086recomendacao-n-018-de-26-de-marco-de-2020. Acesso em: 22 mar. 2021.

BRAVO, Maria Inês Souza. Política de saúde no Brasil. In: MOTA, A.E. et al. (orgs.). Serviço Social e Saúde: formação e trabalho profissional. $3^{a}$ ed. São Paulo: Cortez; Brasília, DF: OPAS, OMS, Ministério da Saúde, 2008. p. 88-110.

CASTRO, M. M. C.; Formação em Saúde e Serviço Social: as residências em questão. Revista Textos \& Contextos, Porto Alegre, n. 2, v. 12, p. 349-360, jul./ dez. 2013. Disponível em: http:// revistaseletronicas.pucrs.br/ojs/index.php/fass/article/view/14429. Acesso em: 04 nov. 2017.

CLOSS. T. T. O serviço social nas residências multiprofissionais em saúde: formação para integralidade? 1.ed. Curitiba: Appris, 2013. 302 p.

CLOSS. T. T. O Serviço Social nas residências multiprofissionais em saúde na atenção básica: formação para a integralidade? 2010. 228 f. Dissertação (Mestrado em Serviço Social). Pontifícia Universidade Católica do Rio Grande do Sul, Porto Alegre, 2010.

CONSELHO FEDERAL DE SERVIÇO SOCIAL (CFESS). Residência em Saúde e Serviço Social: subsídios para reflexão. Série 6 - Trabalho e Projeto Profissional nas Políticas Sociais. Brasília: CFESS, 2017.

DARDOT, Pierre; LAVAL, Christian. A nova razão do mundo: ensaio sobre a sociedade neoliberal. Tradução de Mariana Echalar. 1. ed. São Paulo: Boitempo, 2016.

MENDES, A. G. Residência Multiprofissional em Saúde e Serviço Social. In: SILVA, L. B.; RAMOS, A. (Org.). Serviço social, saúde e questões contemporâneas: reflexões críticas sobre a prática profissional. Campinas: Ed. Papel social, 2013. p.183-199.

RODRIGUES, T. de F. (et. al.). O Serviço Social no Programa de Residência Multiprofissional em Atenção à Saúde da UNIFESP/SP. Revista Serviço Social \& Saúde, v. X, n. 12. Campinas: UNICAMP, dez., 2011.

RODRIGUES, T. de F. Residências multiprofissionais em saúde: formação ou trabalho? Revista Serviço Social \& Saúde, v. 15, n. 1. Campinas: UNICAMP, jan./jun., 2016.

ROSA, S. D. Tecendo os fios da educação e saúde: a Formação Profissional na Residência Multiprofissional em Saúde. 2012. 212 f. Tese (Doutorado em Educação) - Centro de Educação e Ciências Humanas, Universidade Federal de São Carlos, São Carlos, 2012. 
SANTANA, J. P.; CAMPOS, F. E.; SENA R. R. de. Formação profissional em saúde: desafios para a universidade. In: SANTANA, J.P.; CASTRO, J.L. (Org.). Capacitação em

desenvolvimento de recursos humanos de saúde: CADRHU. Natal: EDUFRN, 1999. p. 109-123.

SCHMALLER, V. P. V. et al. Trabalho em saúde, formação profissional e inserção do Serviço Social na residência multiprofissional em saúde da família. Revista Textos \& Contextos, Porto Alegre, n. 2, v. 11, p. 346-361, ago./ dez. 2012. Disponível em:

http://revistaseletronicas.pucrs.br/ojs/index.php/fass/article/view/12362/8651. Acesso em: 24 nov. 2014.

SILVA, L. B. Residência multiprofissional em saúde no Brasil: alguns aspectos da trajetória histórica. Revista Katálysis, Florianópolis, v. 21, n. 1, jan.-abr. 2018. p. 200-209. 